\title{
Review on Synthesis of 3-Substituted 1,2-Benzisoxazole Derivatives
}

\author{
R. A. SHASTRI \\ Post Graduate Department of Chemistry, \\ S.B.E.S. College of Science, Aurangabad-431001, India \\ shastriranjana@yahoo.com
}

Received 14 August 2015 / Accepted 12 September 2015

\begin{abstract}
Benzisoxazole derivatives are oxygen, nitrogen containing heterocycles with wide range of synthetic and pharmaceutical applications, and are famous for biological activities. The high therapeutic properties of these heterocycles have encouraged the medicinal chemist to synthesize a large number of chemotherapeutic agents. 1, 2-Benzisoxazole derivatives can be synthesised by variety of methods, but the most popular method involves, the base catalysed cyclization of $o$ - hydroxy ketoximes or its derivatives. This article aims to review the work reported by chemists under different solvent media and under different conditions and their biological activities.
\end{abstract}

Keywords: 1,2-Benzisoxazoles, $o$-Hydroxy ketoximes, Microwave, Ionic liquid, Antimicrobial activities, Antipsychotic activity

\section{Introduction}

The growing interest in heterocyclic compounds is due to their biological activity. It is well known, heterocyclic moiety play important functions in medicinal chemistry and serves as key template for the development of therapeutic agents with unique properties. Mostly researches have maintained their interest in the synthesis of nitrogen, oxygen and sulphur containing heterocyclic compounds.

One very interesting and promising class of heterocycle is 3 substituted 1,2benzisoxazoles which has significant pharmacological and biological activities such as analgesics $^{1}$, anticonvulsant ${ }^{2,3}$, antipscychotic ${ }^{4,5}$, anticancer ${ }^{6}$, antimicrobial ${ }^{7}$ and also showed affinity for serotonergic and dopaminergic receptors. The 3-( $N$ - benzyl piperidinyl ethyl) 1,2-benzisoxazoles inhibit acetyl cholinesterase hence alleviate memory deficit in alzheimer disease. 1, 2-Benzisoxazoles 3 methane sulphonamide (zonisamide) is an antiseizure agent useful in epilepsy. A typical antipsychotic drugs containing benzisoxazole nucleus includes risperidone, iloperidone and paliperidone. Several 1,2-benzisoxazoles phosphorodiamidates are useful as novel anticancer prodrugs, 1,2-benzisoxazoles are used to treat migraine and neuropathic pain. It is also used by psychiatrists as mood stabiliser to treat bipolar depression ${ }^{8}$. 
Literature survey reveals different synthetic protocols for the synthesis of these compounds. The base catalyzed cyclization of $o$-hydroxy phenyl ketoximes is the most elegant method which involves the attack of phenoxide ion on the nitrogen of oxime or its derivative to give 1,2-benzisoxazole derivative. These methods are usually carried in two steps. Very few methods described the synthesis of 1,2-benzisoxazoles in one step. Such a glamorous history and its medicinal value prompted us to review the convenient methods for the synthesis of 1,2-benzisoxazole derivatives 1977 onwards.

\section{Review}

A series of 3-methyl, 3-ethyl and 3-phenyl derivatives were synthesized by Bhawal, Goswami et al. ${ }^{9}$ by the cyclization of appropriate 2'-hydroxy ketoxime acetates in dry pyridine. This is a three step process. In the first step 2'-hydroxy ketoxime were synthesized from substituted $o$-hydroxyl acetophenones, propiophenones and benzophenones by refluxing with hydroxyl amine hydrochloride in the presence of sodium hydroxide. In the second step, synthesis of 2'hydroxy ketoxime acetate was prepared by treating 2'-hydroxy ketoximes in acetic acid with equimolecular quantity of acetic anhydride. The resulting $o$-hydroxyketoxime acetates were subjected to facile and clean cyclization in the presence of dry pyridine for 3-4 hours to yield 1,2-benzisoxazoles in 90\% yield. All the synthesized compounds were characterized by spectral studies.<smiles>[R]C(=O)c1ccccc1O</smiles>

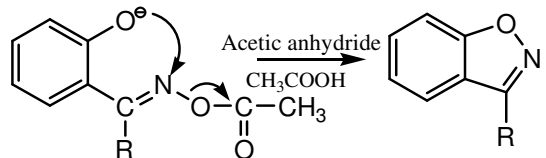

\section{Scheme 1}

Kalkote and Goswami ${ }^{10}$ synthesized 3-hydroxy, 3- methyl and 3-phenyl 1,2- benzisoxazoles by treating appropriate ketoximes with thionyl chloride in the presence of pyridine in anhydrous ether at $0{ }^{\circ} \mathrm{C}$

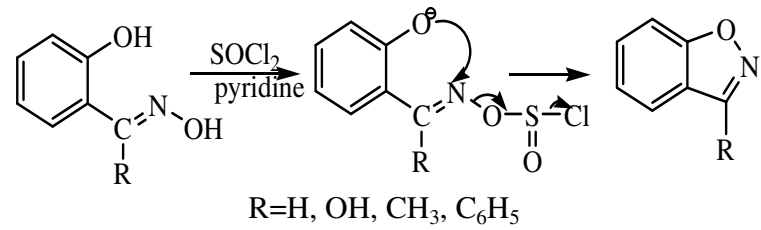

\section{Scheme 2}

Uno et al. ${ }^{11}$ synthesized 3-sulfamoylmethyl-1, 2- benzisoxazole derivatives from 3(bromomethyl)-1,2-benzisoxazoles by the reaction with sodium bisulphite followed by chlorination and amination.

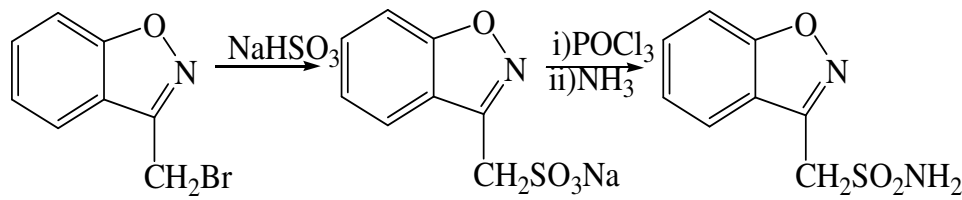

\section{Scheme 3}

Halogenations at 5 position of benzisoxazoles ring showed marked anticonvulsant activity and neurotoxicity. Among these compounds 1,2-benzisoxazole 3 methane sulphonamide (Zonisamide) showed most promising anticonvulsant activity. 
Synthesis of 1,2-benzisoxazole -3-acetamide derivatives were reported by Kazuo Sato, et $a l .{ }^{12}$. Methodology involves synthesis of 1,2-benzisoxazole- 3-acetic acid from hydroxycoumarines by posner reaction which was reacted with 2-2 dimethyl benzylamine to give $N$ - methyl benzyl-1,2-benzisoxazole-3-acetamides. These amides on treating with $n$ butyllithium yielded anion which on halogenation $\left(\mathrm{Br}_{2}\right.$ or $\mathrm{N}$ Chlorosuccinamide) gave $\mathrm{N}-\alpha$ dimethyl benzyl 2-halo 1,2-benzisoxazol-3-yl acetamide and $N$ - $\alpha, \alpha$-dimethyl benzyl-2dihalo,1,2- benzisoxazol-3-ylacetamide. Further alkylation to the $\alpha$ - methylene carbon with alkyl halide yielded $N$ - $\alpha, \alpha$ - dimethyl benzyl-2 methyl-(1, 2-benzisoxazol-3-yl) acetamide. The herbicidal activity was tested on plants Barnyard grass, Brood weed leaf, Hotarui, Slender Spikerush, Urikawa, Mizugayatsuri, Kuroguwai, transplanted seedlings. $N$ - $\alpha, \alpha$-dimethyl benzyl-2-bromo-(1, 2-benzisoxazol-3-yl) derivative was the most effective herbicide whereas all others were mild to moderately active.
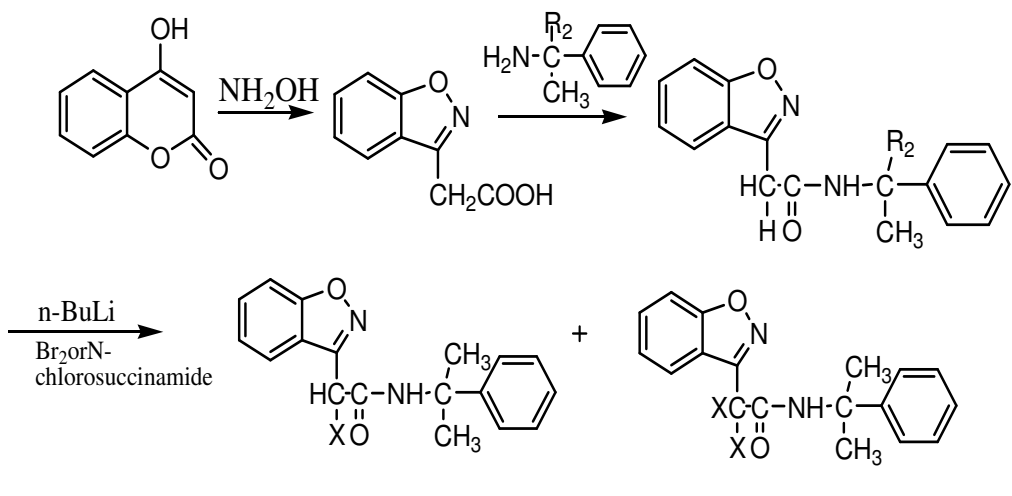

$\mathrm{X}=\mathrm{Bror} \mathrm{Cl}$

\section{Scheme 4}

Synthesis of some new 3-styryl-1,2-benzisoxazoles were reported by Ghiya and Naphade $^{13}$. Substituted chalcones were synthesized by the Claisen- Schmidt condensation of substituted $o$-hydroxy acetophenone and $p$-anisaldehyde, then these chalcones were reacted with hydroxylamine in aqueous alkaline condition and refluxed for 15 minutes, resulting sticky mass was crystallised from benzene. Obtained chalcone oximes were dissolved in methylene chloride treated with silica gel and stirred for $3 \mathrm{~h}$. Slica gel and solvent was removed which yielded 3- methoxy styryl 1,2-benzisoxazole derivatives.

A convenient one pot synthesis of 3-amino 1,2-benzisoxazole derivatives was reported by Palermo ${ }^{14}$. Methodology involves synthesis of $N$-(2-cyano-phenoxy) by treating $o$-halo or $o$-nitrobenzonitrile with hydroxamate anion which in situ undergoes intramolecular cyclization in presence of base to yield 3- amino 1,2-benzisoxazole. Similarly other nuclear substituted analogs were prepared. 
<smiles>[R]c1cc([R9])c(O)c(C(C)=O)c1</smiles>

B $\mathrm{R} 1=\mathrm{CH}_{3} \mathrm{R} 2=\mathrm{NO}_{2}$

Scheme 5<smiles>[R]c1cccc([X])c1C#N</smiles>

$\mathrm{X}=\mathrm{F}, \mathrm{Cl}, \mathrm{NO}_{2}$

\section{Scheme 6}

Shastri and Goswami ${ }^{15}$ developed a new method for the synthesis of 3 substituted 1,2benzisoxazoles. The reaction throws light on transformation of trans-oxime to syn oxime via nitroso oxime tautomerism. Methodology involves conversion of $\mathrm{OH}$ group of o-hydroxyl acetophenones in to tosylates by treating with benzene sulfonyl chloride which on oximation by refluxing with hydroxylamine in pyridine yielded oxime of benzene sulfonate of $o$-hydroxyl ketoximes. These derivatives on refluxing in presence of $\mathrm{NaOH}$ in dioxin for 12 hours yielded 3 substituted 1,2-benzisoxazoles. By this procedure 3 methyl, 3 ethyl and 3 phenyl benzisoxazoles were synthesised. 


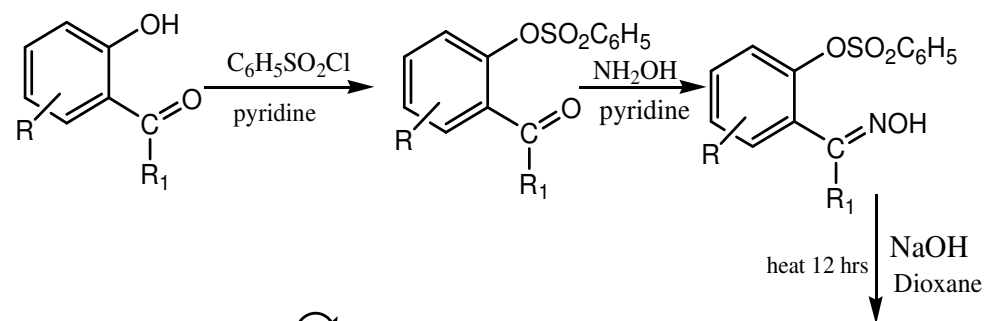

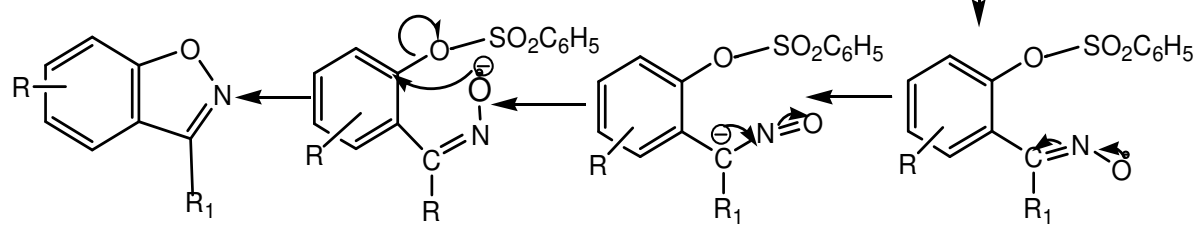

$\mathrm{R} 1=-\mathrm{CH}_{3},-\mathrm{C}_{2} \mathrm{H}_{5},-\mathrm{C}_{6} \mathrm{H}_{5}$

Scheme 7

This methodology was extended for the synthesis of 1,2-benzisoxazole-3-propionic acid with slight modification. For this required $\beta$-salicylopropionic acid was converted in to ester by reacting with dimethyl sulphate in methanol. Further same procedure was adapted.<smiles>O=C(O)CCC(=O)c1ccccc1O</smiles><smiles>COC(=O)CCC(=O)c1ccccc1O</smiles><smiles>CCOc1ccccc1C(=O)CCC(=O)Oc1ccccc1</smiles><smiles>[3H][13C](C)(C)O</smiles><smiles></smiles><smiles>O=Cc1noc2ccccc12</smiles>

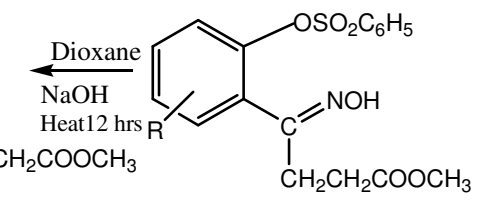

\section{Scheme 8}

The methodology differs from the established methods reported for the synthesis of 1,2-benzisoxazole derivatives. Manish Jain et al. ${ }^{16}$ synthesized a series of 1,2-benzisoxazoles phosphoradiamidates as anticancer prodrugs. Hydroxy coumarines by posner reaction yielded 1,2-benzisoxazol-3-acetic acid which on refluxing with methyl acetate in presence of few drops of sulphuric acid yielded methyl 1,2-benzisoxasol-3-yl acetate which was reduced with $\mathrm{LiAlH}_{4}$ to 2-(1,2-benzisoxasol-3-yl ) ethanol .The resulting derivate in THF treated with $n$-butyl lithium, then this suspension was added to $N, N$-bis (2-chloro-ethyl)-phoshoramidic dichloride in ice bath temperature for $1 \mathrm{~h}$, followed by ammonia bubbling yielded (1,2-benzisoxasol-3yl)ethyl $\mathrm{N}, \mathrm{N}-$ bis(2-chloroethyl)-phosphorodiamidate. Similarly 2-(1,2-benzisoxasol-3yl) ethyl $N, N, N, N$ tetra methyl phosphorodiamidate was synthesized by reacting 2-(1,2-benzisoxasol-3yl ) ethanol in THF treated with $n$-BuLi in ice bath, then drop wise addition of $N, N, N, N$ tetramethyl amido phosphrochloridates was carried and slowly reaction temperature was raised to room temperature a yellow oily residue 2-(1,2-benzisoxasol-3yl) ethyl $N, N, N, N$ tetra methyl phosphoamidate was obtained, similarly 6 methoxy derivatives were prepared. 


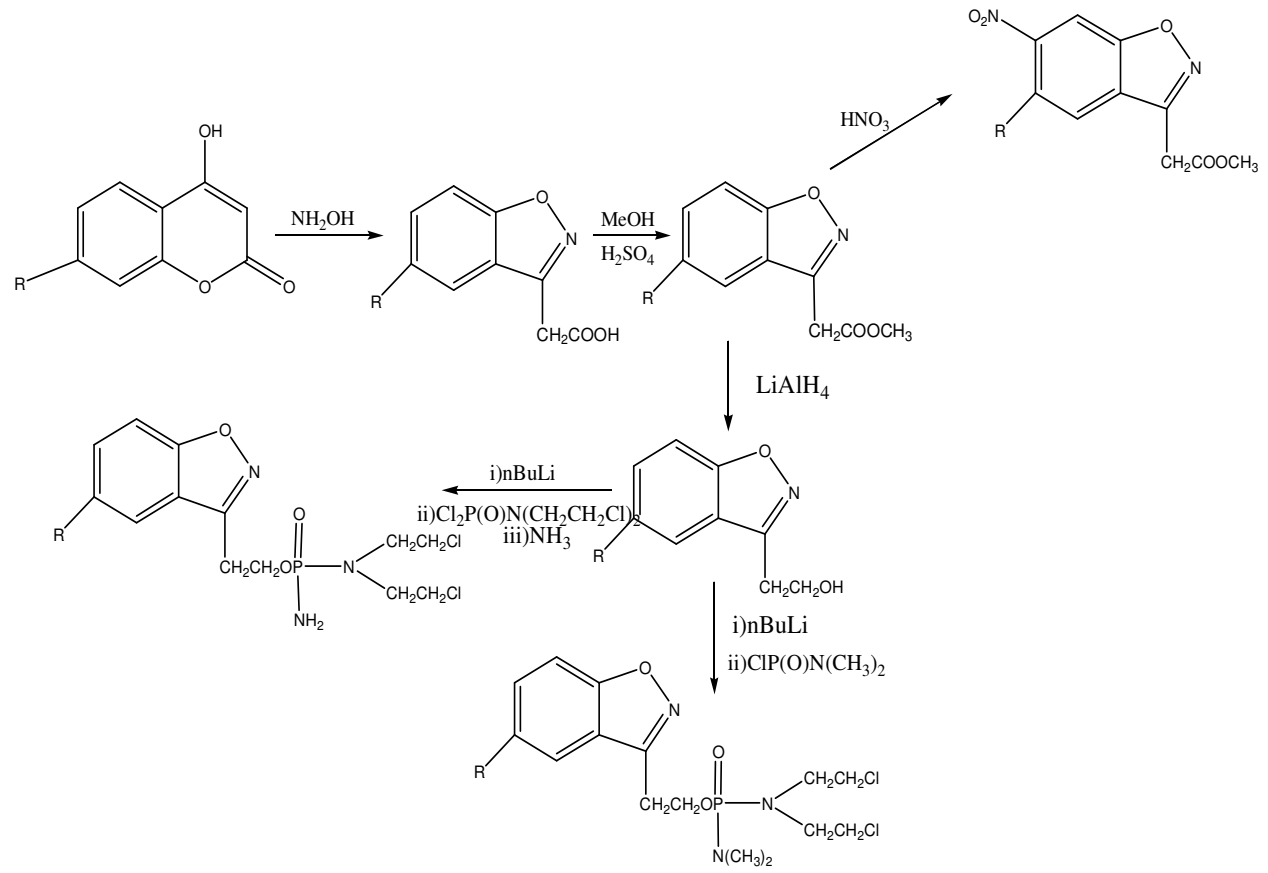

Scheme 9

Both prodrugs undergo reductive metabolism and generates alkylating agents with equal degree under oxic and hypoxic condition in the presence of microsomal cytochrome p-450 / or $\mathrm{p}-450$ reductase. These prodrug also showed in vitro cytoxicity against v-79 cells Shastri and Goswsami ${ }^{17}$ reported synthesis of new 3- $\beta$-bromo ethyl 1,2- benzisosxazoles from 1,2benzisoxazole-3-propionic acid by Hunsdiecker method. 1,2-Benzisoxazole-3-propionic acid was converted in to silver salt and then treated drop wise with bromine in $\mathrm{CCl}_{4}$, stirring was done in ice bath, room temperature and at $40-45^{\circ} \mathrm{C}$ each for half an hour, then heated at $50^{\circ}, 60^{\circ}$ and $70{ }^{\circ} \mathrm{C}$ for one hour and 2 hours respectively. Solid $\mathrm{AgBr}$ obtained was filtered and CTC was removed by vacuum distillation. The solid obtained was crystallised from ethanol. All these compounds were characterized by spectral analysis.
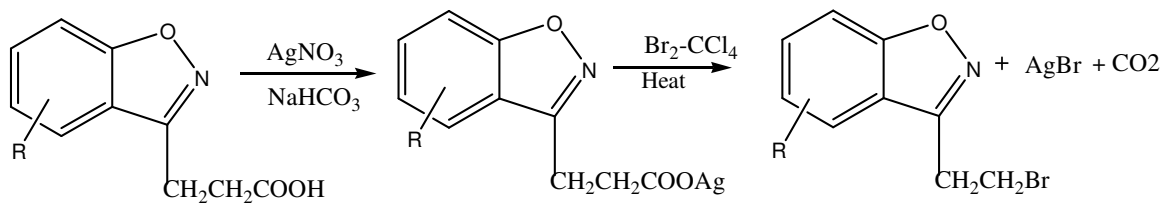

\section{Scheme 10}

Rangappa et al. ${ }^{18}$ synthesized 6-fluro-3-[1-(2-piperidin/pyrrolidin/morpholin/ piperazin1-yl-ethyl) piperidin-4-yl]benzo[d]isoxazole monohydrochloride. Isonipectocic acid on reacting with mixed anhydride (Acetic anhydride and formic acid) at $0-5{ }^{\circ} \mathrm{C}$ yielded $\mathrm{N}$ formyl nipectocic acid. This $N$-formyl nipectocic acid on Friedel Crafts reaction with 1,3 diflurobenzene, $\mathrm{AlCl}_{3}$ yielded 2,4 diflurobenzyl-4-piperidine in quantitative yield, which on oximation with hydroxylamine sulphate in presence of powdered $\mathrm{KOH}$ in situ generates oxime and its subsequent internal cyclization followed by alkaline hydrolysis gave 6- fluro 3-(4-piperidinyl)-1,2benzisoxazole hydrochloride. This 1,2-benzisoxazole derivative on 
condensing with 1-(2-chloro ethyl)piperidin/pyrrolidin/morpholin / piperazine hydrochloride in the presence of anhydrous $\mathrm{K}_{2} \mathrm{CO}_{3}$ at $55-60{ }^{\circ} \mathrm{C}$ for $5 \mathrm{~h}$ in water bath gave the desired compound in quantitative yield and which was identified by spectral studies. All these compounds were found to be potent acetyl cholinesterase inhibitors.

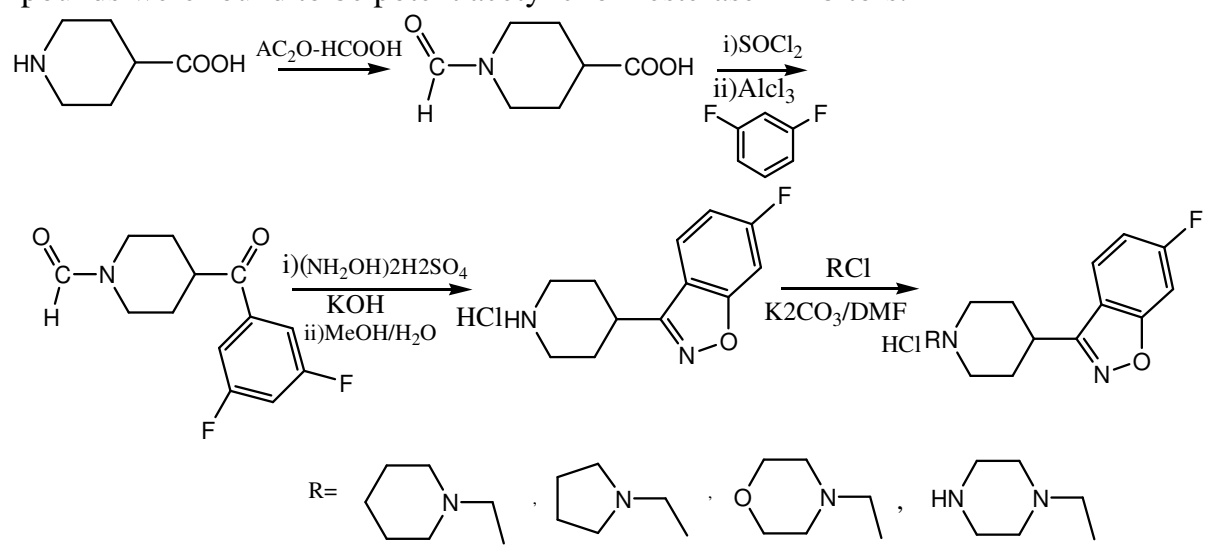

Scheme 11

Verra Reddy Arva et al. ${ }^{19}$ developed a simple and economical process for the preparation of 1,2-benzisoxazole-3-methane sulfonate from sulfone oximes which can be used for the commercial production of zonisamide an important anticonvulsant drug. Methyl salicylates on condensation with methyl sulfonyl chloride yielded methane sulfonate derivative which on reacting with $\mathrm{NaH}$ and DMSO cyclised to 1,2 benzoxanthin $-4(3 H)$ 1, 2, 2 dioxides which was characterized from analytical spectral data. This on oximation with hydroxylamine hydrochloride in sodium acetate yielded sulfone oxime. Sulfone oxime smoothly rearranges to 1, 2-benzisoxazole-3-methane sulfonate by reacting with sodium methoxide in methanol. The 1,2- benzisoxazole-3-methane sulfonate on condensing with $\mathrm{POCl}_{3}$ followed by ammonolys is converted to 1,2- benzisoxazole- 3-methane sulphonamide (Zonisamide).

Shastri et $a{ }^{20}{ }^{20}$ reported a new rapid, cost effective and ecofriendly synthesis of 3substituted 1, 2-benzisoxazoles from $o$ - hydroxyl ketoximes in solvent free conditions using silica gel as solid support under microwave irradiation. This is a two step process, in the first step $o$-hydroxy ketoximes were prepared by the oxidation of $o$-hydroxyl carbonyl compounds. In the second step $o$-hydroxy ketoximes by dissolving in minimum quantity of dichloro methane treated with silica gel (60-120 mesh ) impregnated with sodium carbonate, subjected to microwave irradiation for 3-4 minutes at $100 \%$ power $(2450 \mathrm{MHz})$ with intermittent cooling. Product was recovered by extracting with $\mathrm{CH}_{2} \mathrm{Cl}_{2}$ and solvent was removed under reduced pressure yielded 1,2-benzisoxazole derivatives in 90-95\% yield. All the synthesized compounds were characterized by spectral studies.

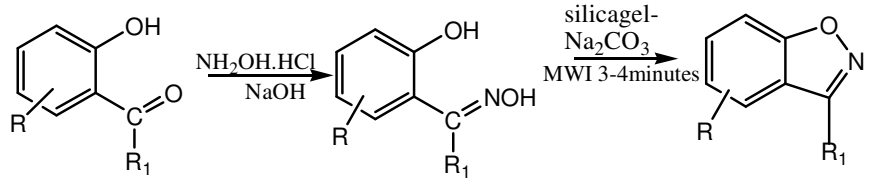
$\mathrm{R} 1=\mathrm{CH}_{3}, \mathrm{C}_{2} \mathrm{H}_{5}, \mathrm{C}_{6} \mathrm{H}_{5}$ 
Shastri and Varudkar ${ }^{21}$ reported a new convenient and eco-friendly synthesis of 3-propene 1, 2-benzisoxazole derivatives. It involves three steps. Firstly 1-(2'-hydroxy aryl)-2-butene-1ones were synthesized by Claisen-Schmidt condensation of substituted $o$-hydroxy acetophenones and acetaldehyde in the presence of sodium hydroxide. The resulting butenenone derivatives were refluxed with hydroxylamine in presence of sodium hydroxide to yield 1-(2'hydroxy aryl)-2 butene-1 oximes, which were subjected to a facile and clean cyclization by microwave irradiation for 3-4 minutes on solid silica gel (60-120mesh) support impregnated with sodium carbonate afforded 3-propene 1,2-benzisoxazole derivatives in considerable yield. All the synthesized compounds were screened for antimicrobial activity and showed potent to weak antibacterial activity and all compounds exhibit marked antifungal activity.<smiles>[R]c1cccc(O)c1C(C)=O</smiles><smiles>C=CC(=O)c1ccccc1NOC(C)C</smiles>

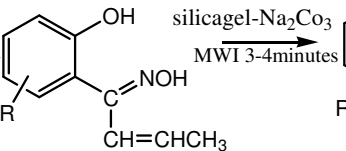<smiles>CC=Cc1noc2ccccc12</smiles>

\section{Scheme 13}

Shingare $e t a l .^{22}$ reported a simple, environmentally benign method for the synthesis of 3- methyl,3ethyl,3 phenyl 1,2-benzisoxazoles in the presence of catalytic quantity of basic ionic liquid 1-butyl-3-methyl imidazolium hydroxide $([\mathrm{bmim}] \mathrm{OH}]$ under the influence of microwave irradiation in excellent yields. A mixture of ketoxime, acetic anhydride \& [(bmim $) \mathrm{OH}]$ were irradiated in microwave oven for 30-60 seconds with intermittent cooling. The progress of the reaction was monitored by TLC and the product was extracted with diethyl ether \& recrystallised.

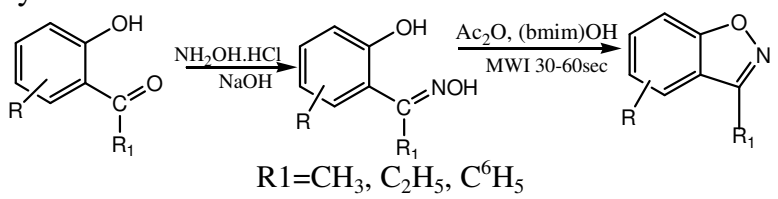

Scheme 14

Rangappa et al. $^{23}$ synthesised a series of 6-fluoro-3-(4-Piperidinyl)-1,2-benzisoxazole derivatives. The reaction of isonipecotic acid with mixed anhydride at $0-5^{\circ} \mathrm{C}$ for $14 \mathrm{~h}$ yielded $N$-formylnipecotic acid. In the second step Friedel crafts acylation was carried by adding acid chloride to the mixture of 1, 3-difluoro benzene, $\mathrm{AlCl}_{3}$ in $\mathrm{CH}_{2} \mathrm{Cl}_{2}$ as a solvent at $0-5{ }^{\circ} \mathrm{C}$ which yielded 2,4-difluorobenzoyl 4-piperidine in quantitative yield which on treating with $\mathrm{NH}_{2} \mathrm{OH}$ sulphate in powdered $\mathrm{KOH}$ in situ generates oxime, which subsequently undergoes internal cyclization followed by hydrolysis yielded 6-fluoro-3-(4-piperidinyl)-1, 2 benzisoxazole. The nucleophilic substitution reaction of 6-fluoro-3-(4-piperidinyl)-1,2 benzisoxazole with different aromatic and heterocyclic acid chlorides were carried in presence of triethyl amine and $\mathrm{CH}_{2} \mathrm{Cl}_{2}$ as solvent yielded (4-(6-fluorobenzisoxaxol-3-yl) piperidin-1-yl) morphilino/4methyl piperazin-1-yl/pyrrolidin-1-yl/ $p$-tolyl/piperidin-1yl/3methoxy phenyl/2fluorophenyl/piperidin-1-yl/3,5 dinitro pheny $1 / 2,6$ difluoro phenyl/ 2,4 dichloro phenyl methanone in $81-93 \%$ yield.

All the compounds synthesized were evaluated for antiproliferative activity by MTT assay. Antiproliferative effects were tested against human fibroblast cells and carcinoma cells. SAR studies revealed that, the substitution at $N$-terminal of 6-fluoro-3-(4-piperidinyl) 1,2-benzisoxazole by the heterocyclic ring has prominent anti proliferative activity. Compounds (4-(6-fluorobenzisoxozol-3-yl)piperidin-1-yl)(morpholino/pyrrolidin-1-yl/2,6difluorophenyl) methanone showed potent antiproliferative activity. 


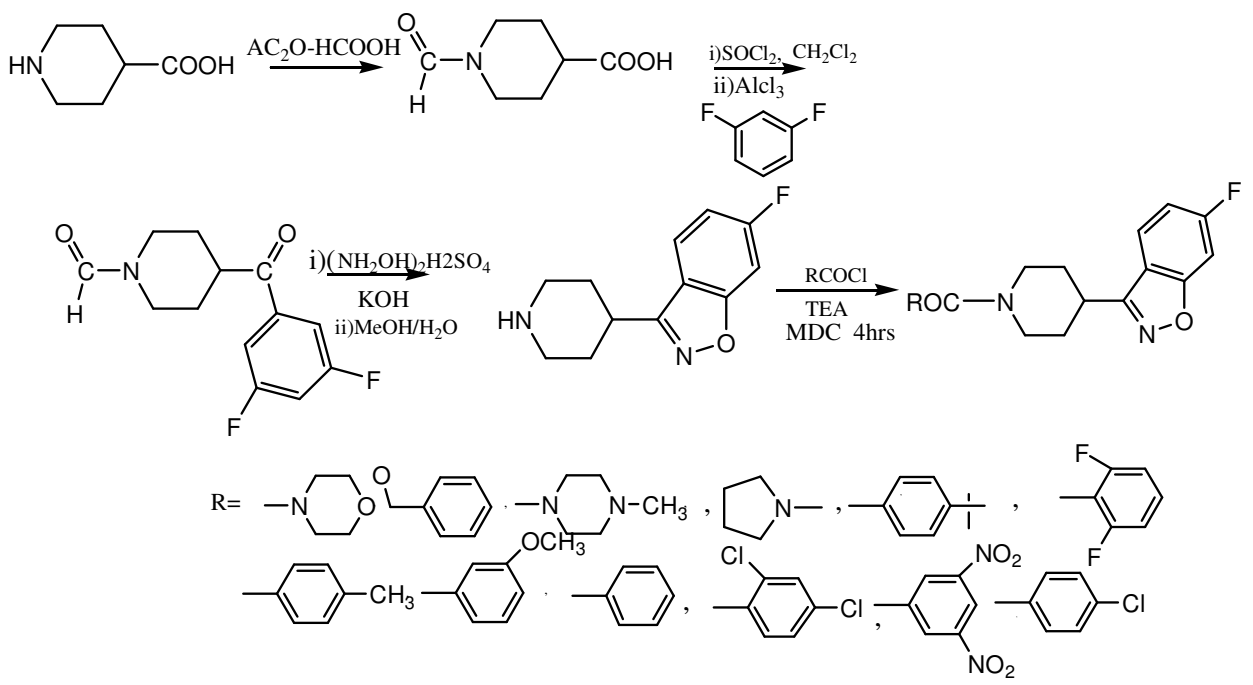

Scheme 14

Goswami et $a .^{24}$ reported the synthesis of 3- methoxymethyl/3- bromomethyl/3- nitro methyl/3- methanol 1,2-benzisoxazole derivatives. For the reaction, o.hydroxy $\omega$ methoxy acetophenones were synthesized by the alkaline hydrolysis of 3-methoxy flavones, which on oximation with hydroxylamine hydrochloride in alkaline medium, yielded $o$. hydroxy $\omega$ methoxy acetophenone oxime. The product was further subjected for acetylating with acetic anhydride in acetic acid to give corresponding $o$-hydroxy $-\omega$-methoxy acetophenone oxime acetate. These compounds on refluxing in dry pyridine underwent cyclizaiton to give 3methoxymethyl 1, 2- benzisoxazole derivatives. The structures of synthesized compounds were determined by spectroscopic data and elemental analysis. 3-Methoxy methyl 1,2benzisoxazoles on refluxing with $\mathrm{HBr}$ in $\mathrm{CH}_{3} \mathrm{COOH}$ for 8 hrs gave 3-bromo methyl 1,2benzisoxazoles.

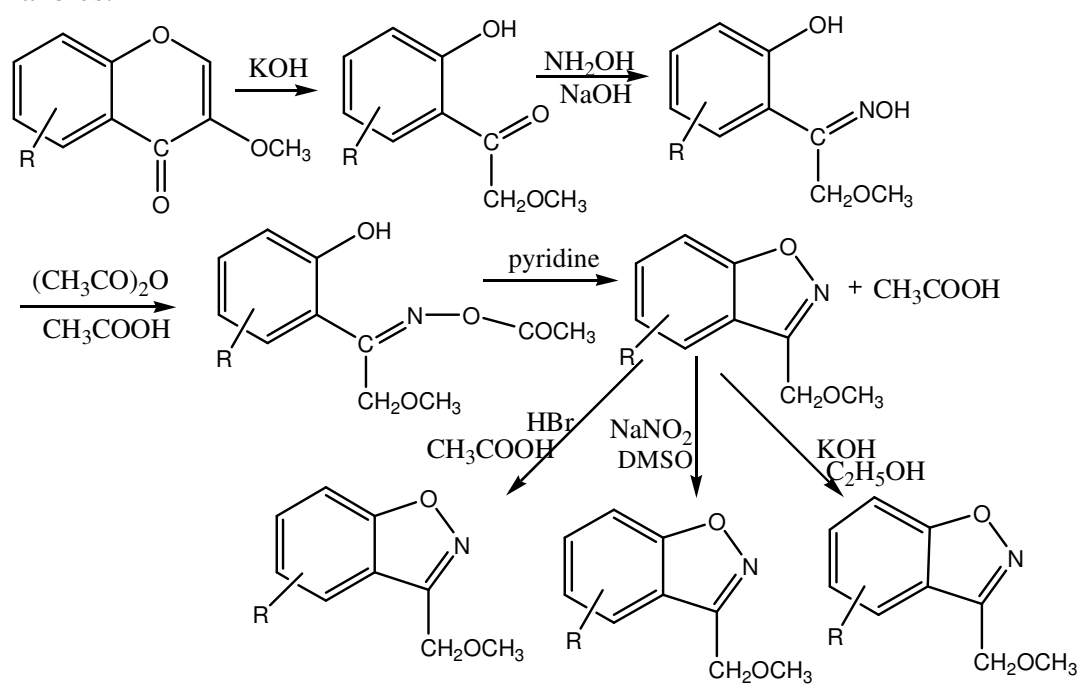

Scheme 15 
Further the reaction of 3-methoxy methyl 1,2- benzisoxazoles with $\mathrm{NaNO}_{2}$ in DMSO and aq. $\mathrm{KOH}$ yields the 3- nitro methyl, 3- hydroxy methyl 1,2-benzisoxazoles respectively. The structures of newly synthesized compounds were established on the basis of their spectral data.

Microwave promoted synthesis of 3- amino substituted 1,2-benzisoxazoles was reported by smith et $a l^{25}$. For the reaction, required 3 chloro 1, 2-benzisoxozoles were prepared by heating 3- hydroxy 1,2-benzisoxazole in microwave oven in quantitative yield. The resulting 3-chloro1,2-benzisoxazoles were subjected for microwave promoted nucleophilic substitution with substituted amine to yield 3- amino 1, 2-benzisoxazoles.<smiles>[R]c1ccc2onc(O)c2c1</smiles><smiles>CC(C)C1CCCC1C</smiles><smiles></smiles><smiles>C[10NH]</smiles><smiles>[R]CC1C(N[R17])=NOc2ccccc21</smiles>

\section{Scheme 16}

Veera Reddy Arava et $a l .^{26}$ developed an efficient and simple method for the synthesis of 3chloromethy-1,2- benzisoxazoles by Boekelheide rearrangement. The reaction proceeds in two steps. In the first step 3 alkyl 1, 2- benzisoxazole -2-oxide was synthesized by stirring $o$-hydroxy ketoximes in aqueous sodium hydroxide with sodium hypochlorite at temperature $0-10{ }^{\circ} \mathrm{C}$ for 30 minutes which precipitated 3-methyl-1,2- benzisoxazoles $N$-oxide. In the second step 3 methyl 1,2- benzisoxazole $\mathrm{N}$-oxide in $\mathrm{CH}_{2} \mathrm{Cl}_{2}$ at $20{ }^{\circ} \mathrm{C}$ was treated drop wise with $\mathrm{POCl}_{3}$ and then triethylamine. The resulting mixture was refluxed 48 hours, \& extracted with methylene chloride in excellent yields. The structures of all products were elucidated by spectroscopic data.

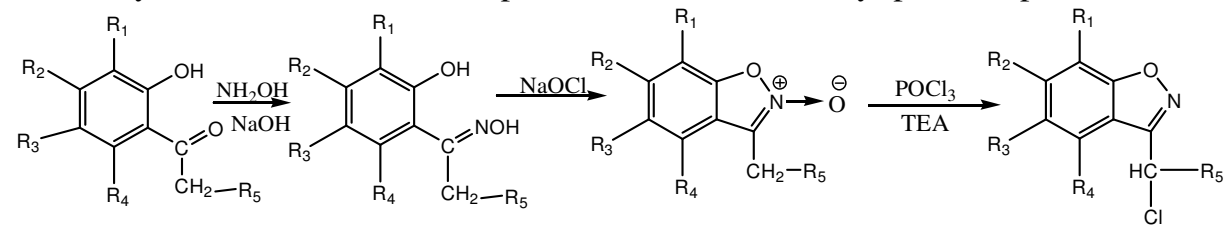

Scheme 17

Synthesis of some 6 amino 3 substituted 1, 2-benzisoxazoles was reported by Gopal $\operatorname{Garg}^{27}$ et al. Substituted chalcones were synthesized by the Claisen Schmidt condensation of 4-amino-2-hydroxy acetophenones with substituted aldehydes. Then these chalcones were reacted with $\mathrm{NH}_{2} \mathrm{OH}$ in basic condition afforded chalcone oxime which was subjected for microwave irradiation. A ketoxime, silicage gel impregnated with $\mathrm{Na}_{2} \mathrm{CO}_{3}$ were irradiated in microwave oven for 3-4 minutes with intermittent cooling \& the product was extracted with $\mathrm{CH}_{2} \mathrm{Cl}_{2}$ and recystallised. All the synthesized compounds were characterized by spectral data. These compounds were screened for antimicrobial activity, componds a, b, e exhibit good antimicrobial activity.

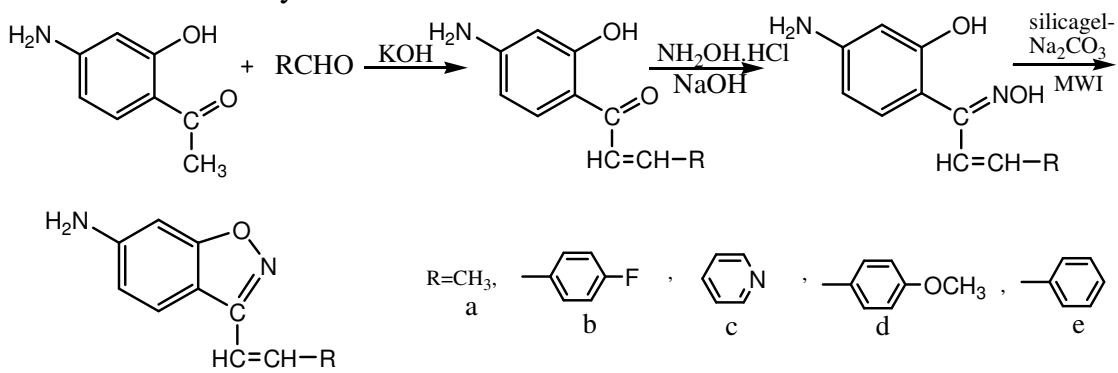

Scheme 18 
Shastri $^{28}$ reported synthesis of some novel 2-(2-benzisoxazol-3-yl)ethyl)-1 $H$ benzimidazoles. 1,2-Benzisoxazole-3-propionic acid on condensation with $o$-phenylene diamine hydrochloride by Phillips method yielded 2-(2-benzisoxazol-3-yl)ethyl)-1 $H$-benzimidazoles in good yield which was identified by NMR spectroscopy \& elemental analysis. These compounds were screened for the antimicrobial activity and showed potent antifungal agent.

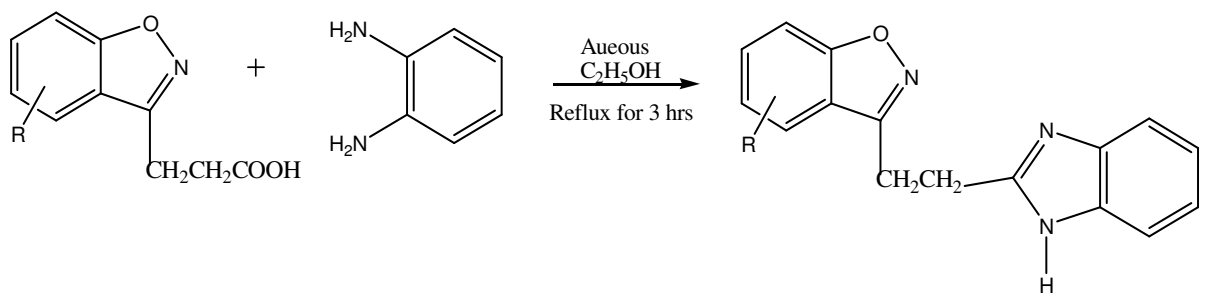

\section{Scheme 19}

Antibacterial activity against bacterial strains such as E.coli and S.aureus results showed all compounds have moderate to weak antibacterial activity. Antifungal activity against Aspergillus Niger, P.chrysogenum, Fusarium moneliforme, Aspergillus flavus all compounds showed promising antifungal activity.

Kanchugara et al. ${ }^{29}$ synthesized a series of 4-(4- [6-fluorobenzo[d] isoxazol-3-yl) piperidine -1-carbonyl) -3- methyl 8-(phenyl substituted) 1- oxa-8-azaspiro [4, 5] dec-3en-2one and evaluated for their antibacterial, antioxidant and anti-inflammatory activities.

Synthesis involves cyclocondensation of ter-butyl 4-oxopiperidine -1-carboxylate with dimethyl 2 succinate in the presence of sodium methoxide in THF gave 8azaspiro[4,5]dec-3 ene-4,8 dicarboxylate in quantitative yield. On selective hydrolysis with hydroxide in methanolic water it yielded 8-(ter-butoxycarbonyl)-3 methyl 2-oxo 1-oxa-8-azaspiro $[4,5]$ dec-3-ene-4 carboxylic acid. This compound was condensed with 6-fluoro-3-(piperidine -4-yl)benzo (d)isoxazole hydrochloride in presence of of 1ethyl -3- [3 dimethyl aminopropyl carbodimide hydrochloride \&hydroxyl benzotriazole in $\mathrm{CH}_{2} \mathrm{Cl}_{2}$ afforded tert-butyl4-(4- [6-fluorobenzo[d] isoxazol-3-yl) piperidine -1carbonyl) -3- methyl2-oxo-1- oxa-8-azaspiro [4,5] dec-3-ene-8 carboxylate .This was treated with saturated solution of $\mathrm{HCl}$ in ether to yield 4-(4-[6-fluorobenzo[d] isoxazol3-yl)piperidine-1-carbonyl)-3-methyl-1 oxa-8-azaspiro[4,5]dec -3-en-2one hydrochloride .These derivatives in $\mathrm{CH}_{2} \mathrm{Cl}_{2}$ treated with various sulphonyl chloride at $0{ }^{\circ} \mathrm{C}$ for $3-4$ hours yielded 4-(4- [6-fluorobenzo[d] isoxazol-3-yl) piperidine-1-carbonyl)-3-methyl 8(phenyl substituted) 1-oxa-8-azaspiro[4, 5]dec-3-en-2one .Compounds were extracted with $\mathrm{CH}_{2} \mathrm{Cl}_{2}$ \& purified by column chromatography.

These compounds were evaluated for antibacterial, antioxidant and anti-inflammatory activites. It was found all compounds exhibit moderate antimicrobial activity against $E$. Coli, Klebsiella pneumonia, Salmonella typhi, Shigella flexinen and B. Subtilis. These molecules were also evaluated for antioxidant activity using 2,2-diphenyl 1-picryl hydrazyl scavenging ,super oxide scavenging assays, benzisoxazole bearing methyl, methoxy group exhibited prominent antioxidant activity. Benzisoxazoles having electron withdrawing group such as nitro group showed good antinflammatory activity. 


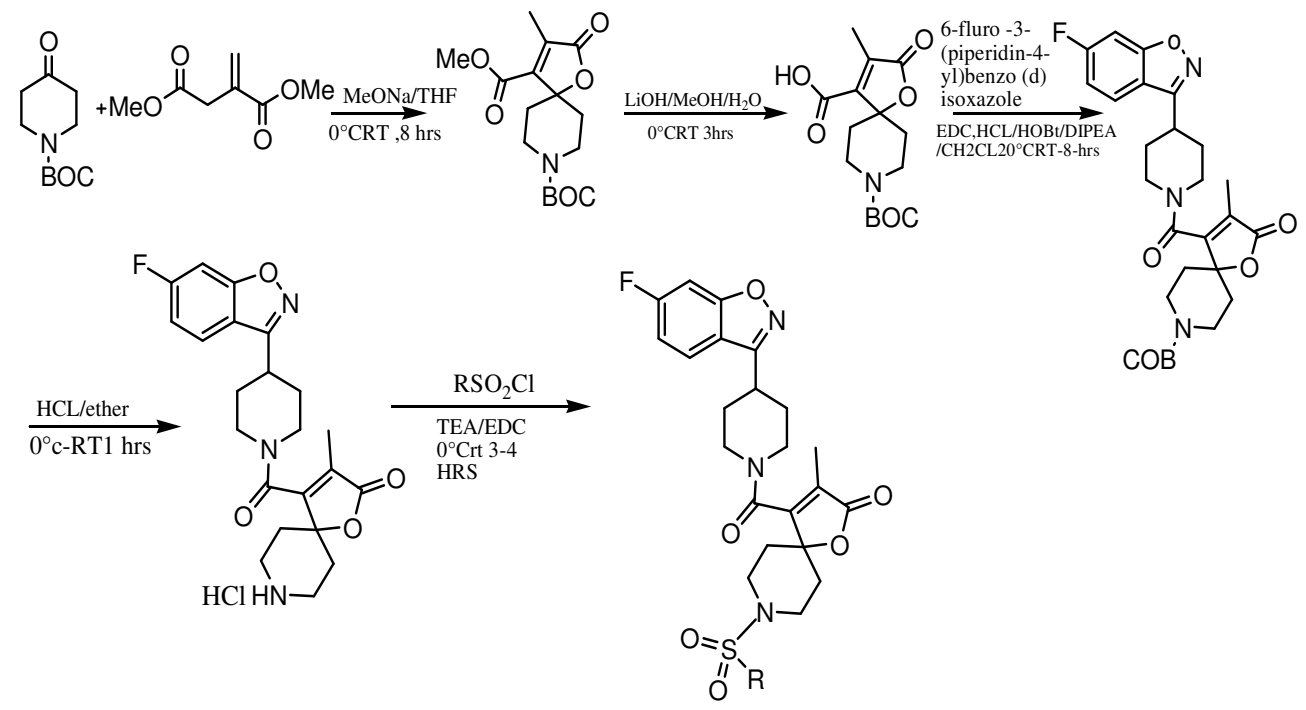

\section{Conclusion}

Scheme 20

1,2-Benzisoxazole derivatives are well known and important heterocyclic compounds in medicinal field; hence various derivatives have been synthesized. The benzisoxazoles scaffold and its analogues are important pharmacophores which are found in biologically active compounds which stimulated the research activity in this field. The manuscript is a brief review about different methods, for the synthesis of biologically active 1, 2benzisoxazole derivatives.

\section{References}

1 Hasegawa H, Curr Med Res Opin., 2004, 20(5), 577-580; DOI:10.1185/030079904125003313

2 Masuda Y, UtsuiY, Sharashi Y, Karasawa T, Yoshida K and Shimizu M, Epilepsia, 1979, 20(6), 623-633; DOI:10.1111/j.1528-1157.1979.tb04846.x

3 Uno Hitoshi Kurukova Mikio, Masuda and Yoshinobu, J Med Chem., 1979, 22(2), 180-183; DOI:10.1021/jm00188a011

4 Vanden Bossche G, Gelders Y G and Heylen S L, Acta Psiquiator Pscicol Am, 1990, 36, 1325.

5. Shimizu M, Karasawa T, Masuda M and Oka M, Expentia, 1974, 30(4), 405.

6 Jain M and Kwon C H, J Med Chem., 2003, 46(25), 5428-5436; DOI:10.1021/jm020581y

7 Thakar K A and Bhawal B M, Curr Sci., 1978, 47, 950

8 Lehman A F, Lieberman J A, Dixon L B, McGlashan T H, Miller A L, Perkins D O and Kreyenbuhl, Am J Psychiatry, 2004, 161(2 Suppl), 1-56.

9 Thakar K A, Goswami D D and Bhawal B M, Indian J Chem., 1977, 15B, 1058.

10 Kalkote U R and Goswmi D D, Aust J Chem., 1977, 30, 1847-1850.

11 Uno H ,Kurokawa M , Masuda Y and Nishimura H, J Med Chem., 1979, 22(2), 180-183.

12 Kazuo Stato, Toyokoni Honma and Soji Sugai, Agric Biol Chem., 1985, 49(12), 3563-3567; DOI:10.1271/bbb1961.49.3563

13 Ghiya B J and Naphade V J, Indian J Chem., 1987, 26, 583-584. 
14 Palermo M G, Tetrahedron Lett., 1996, 37(17), 2885-2886; DOI:10.1016/00404039(96)00425-X

15 Shastri R A and Goswami D D, Indian J Heterocyclic Chem., 2001, 11, 51-54

16 Monish Jain Chul and Hoon, J Med Chem., 2003, 46(25), 5428-5436; DOI:10.1021/jm020581y

17 Shastri R A and Goswami D D, Indian J Hetero Chem., 2004, 13, 277-278

18 Basappa, Mantelingu K ,Sadashiva M P and Rangappa K S, Indian J Chem., 2004, 43B, 1954-1957

19 Reddy V A, Sripalli U B, Nadkarni V and Chinnapillia, Beilstein J Org Chem., 2007, 3(20); DOI:10.1186/1860-5397-3-20

20. Shastri R A, Pedgaonkar S V, Selukar S S and Jadhav S B, J Indian Chem Soc., 2008, 85, 574-576

21. Shastri R A and Varudkar J S, Indian J Chem., 2009, 48B, 1156-1160

22. Shelke K F,Sapkal S B ,Shitole N V, Shingate B B and Shingare M S, Syn Org Cотти., 2009, 2(3), 72-78.

23. Benka Prasad S B , Vinaya K ,Anandkumar C S, Swarup S and Rangappa K S, Invest New Drug., 2009, 27(6), 534-542; DOI:10.1007/s10637-008-9205-5

24. Varudkar J S, Goswami D D and Shastri R A, Indian J Heterocyclic Chem., 2009, 18, 337-340.

25. Smith J A, Le G, Jones E D and Deadman J, Future Med Chem., 2010, 2(2), 215-224; DOI:10.4155/fmc 09.167

26. Reddy V A, Gorentla L, Sripalli U B and Dubey P, Indian J Chem., 2011, 50B, 119-125

27. Sharama A, Gupta S P, Upmanyu N, Jain S and Garg G, Der Pharm Chemica, 2011, 3(3), 253-264.

28. Shastri R A, Indian J Chem., 2013, 52B, 160-163.

29. Shivprasad C M, Swamy J, Swaroop T R, Chakrabhavi D M, Rangaswamy R, Kothanahally S S and Rangappy K S, Eur J Chem., 2014, 5(1), 91-95; DOI:10.5155/eurjchem.5.1.91-95.866 